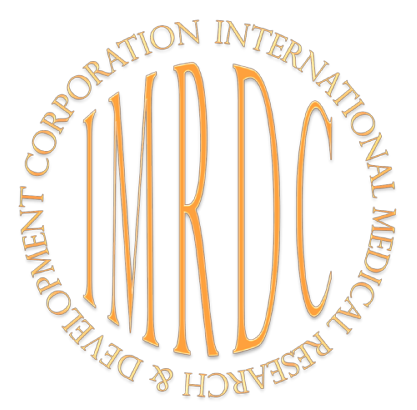

\title{
The Outcomes of Very Early Preterm Births in the Republic of Sakha (Yakutia)
}

\author{
Nyurguyana S. Baisheva*1; Natalia I. Douglas, $\mathrm{PhD}, \mathrm{ScD}^{1}$; Tatiana Y. Pavlova, $\mathrm{PhD}^{2}$; \\ Anisia I. Yakovleva ${ }^{3}$; Tatiana E. Burtseva, $\mathrm{PhD}, \mathrm{ScD}^{4}$ \\ ${ }^{1}$ North-Eastern Federal University \\ ${ }^{2}$ Ministry of Health of Republic of Sakha (Yakutia) \\ ${ }^{3}$ Republican Hospital № 1 - National Center of Medicine, the Perinatal Center \\ ${ }^{4}$ Yakutsk Research Center for Complex Medical Problems \\ Yakutsk, the Sakha Republic (Yakutia), Russia
}

\begin{abstract}
Protection of maternal and child health is a special health care industry. It largely determines the future of the nation. Therefore, it is an important matter of the state. This article presents an analysis of cases of very early preterm births (VEPB) and their outcomes in 2012-2014 in the Republic of Sakha (Yakutia). Retrospective analysis of the cases of VEPB and of the status of health of the babies born before 28 weeks of gestation was conducted during the research. The group at risk of VEPB consisted of women with burdened obstetric and gynecological history. The main causes of VEPB were premature amniorrhexis in pregnant women with carriage of infections and life-threatening severe pre-eclampsia. In the structure of morbidity of very preterm babies the first place among the main diseases belongs to perinatal lesion of central nervous system, the second place belongs to respiratory distress syndrome, and the third place to infectious and inflammatory diseases. In the structure of death, $57.1 \%$ of fatal cases are babies with a term of gestation less than 28 weeks. The causes of mortality were respiratory distress syndrome, congenital pneumonia, and intraventricular hemorrhage. (Int J Biomed. 2016;6(1):56-59.)
\end{abstract}

Keywords: preterm birth; very early preterm birth; very low birth weight; extremely low birth weight.

\section{Introduction}

In the current unfavorable demographic situation and with the health of women of childbearing age in Russia deteriorating, the problems of preservation of the life and health of each baby and reduction of infant mortality are especially relevant [1]. Preterm births (PB) are the leading cause of perinatal morbidity and mortality in the world and one of the most important problems of modern health care [2,3]. According to the WHO classification, very early preterm births (VEPBs) are deliveries which take place between 22 and 27 weeks of pregnancy; in this case the newborns have extremely low birth weight (ELBW) from 500 to $999.0 \mathrm{~g}$. Deliveries in the term of 28-33 weeks are early preterm births (EPB), in

*Corresponding author: Nyurguyana S. Baisheva, Senior lecturer at Department of Obstetrics and Gynecology. North-Eastern Federal University. Yakutsk, the Sakha Republic (Yakutia), Russia. E-mail: kosmos80-80@mail.ru
34-37 weeks are PB. Every year 20 million babies are born prematurely and $0.4 \%-0.5 \%$ of them have ELBW. In Russia, PBs range from $4 \%$ to $16 \%$, and $0.3 \%$ of such newborns have ELBW [4]. With adoption of the order of the Russian Health Ministry №1687n [5], the problem of VEPB in the Republic of Sakha (Yakutia) (RS (Y)) became particularly acute.

Thus, in 2012, the perinatal mortality rate increased from 8.4 to 13.0 per 1000 born alive and dead in the region. In 2013 and 2014, this rate was respectively 10.8 and 10.0 per 1000 born alive and dead. There were 496 PBs in 2012; the proportion of VEPBs was $22.7 \%$. In 2013, the proportion of VEPBs was $17.6 \%$, and in 2014 it was $6.12 \%$. Premature babies of Yakutia are being nursed on 40 beds of the Department of Pathology of Newborn and Premature Babies (DPNaPB) of the Perinatal Center (PC) at the State Budget Institution of RS(Y) "Republican Hospital №1 - National Center of Medicine (NCM)." Children from the entire region are transported there. Thus, the problem of VEPB and the 
outcome is actually not only for the health authorities but also for the social services and requires deep scanning for development of modern preventive measures.

The aim of this study was an assessment of the status of health of the women and their babies born before 28 weeks of gestation, and the identification of very early miscarriage risk factors. The research is based on the records of the marked PC taken in the period from 2012 to 2014.

\section{Materials and Methods}

We conducted a retrospective analysis of occurrence of very early miscarriage and study of health of extremely preterm infants born before 28 weeks of gestation who were hospitalized in the PC in 2012-2014.

Statistical analysis was performed using the statistical software «Statistica» (v6.0, StatSoft, USA). Baseline characteristics were summarized as frequencies and percentages for categorical variables. Group comparisons with respect to categorical variables are performed using chisquare tests or, alternatively, Yates' $\chi 2$ when expected cell counts were less than 5. A probability value of $P<0.05$ was considered statistically significant.

The study was conducted in accordance with ethical principles of the Declaration of Helsinki and approved by the North-Eastern Federal University Ethics Committee.

\section{Results and Discussion}

In 2014, 16,948 childbirths were accepted in the medical institutions of RS (Y) and 1,172(6.9\%) babies were born prematurely (Table 1).

\section{Table 1.}

The number of births in RS (Y) in 2013-2014

\begin{tabular}{|l|c|c|c|}
\hline \multicolumn{1}{|c|}{ Variable } & $\begin{array}{c}2012 \\
(\mathrm{n} / \%)\end{array}$ & $\begin{array}{c}2013 \\
(\mathrm{n} / \%)\end{array}$ & $\begin{array}{c}2014 \\
(\mathrm{n} / \%)\end{array}$ \\
\hline Number of preterm births & $1160 / 6.85$ & $1078 / 6.5$ & $1172 / 6.92$ \\
\hline Number of other births & $15762 / 93.14$ & $15500 / 93.5$ & $15776 / 93.1$ \\
\hline Total number of births & $16922 / 100$ & $16578 / 100$ & $16948 / 100$ \\
\hline
\end{tabular}

In the period from 2012 to 2014,82 women had VEPB in the PC. Overall, $54.66 \%$ of the women were from the rural area and $46.34 \%$ were from the city. VEPB was common in the age group of $19-28$ years $(42.46 \%)$. The early turnout at the dispensary registration (before 12 weeks of the pregnancy period) was $60.97 \%$. Overall, $68.3 \%$ of the women had chronic diseases of the female genital organs, $37.75 \%$ had medical abortions in the anamnesis, $28.1 \%$ - miscarriages, $4.87 \%$ - experienced fetal death, and $15.85 \%$ - PB. Extragenital diseases were found in all of the cases in the studied group: $75.6 \%$ of the women had urinary tract diseases, $54.87 \%$ cardiovascular diseases, 36.58\% - gastrointestinal diseases, $19.51 \%$ - anemia, $8.53 \%$ - respiratory system diseases, and $2.43 \%$ - endocrinopathies. Sexually transmitted infections were found in almost all the studied cases.

On average, $55.06 \%$ of the women entering an obstetric hospital had a severe condition; $87.33 \%$ had such a condition due to the severe pre-eclampsia. The causes of VEPB were premature amniorrhexis $(42.6 \%)$, premature abruption of a normally located placenta $(14.23 \%)$, threat of fetal asphyxia $(9.13 \%)$, and isthmic-cervical incompetence (6.06\%). On average, $18.74 \%$ of the women had independent childbirth, $81.26 \%$ - surgical delivery (cesarean section), and $13.41 \%$ emergency childbirth. The main reasons for early deliveries (in 22-27 weeks) were severe pre-eclampsia (38.63\%), premature abruption of a normally located placenta $(9.1 \%)$, and premature amniorrhexis (16.23\%).

The majority of mothers (42.2\%) had a secondary education, $55.06 \%$ of the women were married, and 31 women (37.8\%) smoked tobacco.

Due to the effective implementation of routing of the women in labor who have severe extragenital pathology and routing of women with a threat of PB in the RS (Y), there was an increase in preterm infants with ELBW born at the PC (Table 2).

Table 2.

The number of premature infants hospitalized to the DPNaPB (PCNCM) from maternity wards of $R S(Y)$

\begin{tabular}{|l|c|c|c|}
\hline \multicolumn{1}{|c|}{ Variable } & $\begin{array}{c}2012 \\
(\mathrm{n} / \%)\end{array}$ & $\begin{array}{c}2013 \\
(\mathrm{n} / \%)\end{array}$ & $\begin{array}{c}2014 \\
(\mathrm{n} / \%)\end{array}$ \\
\hline Maternity ward of PC NCM & $89 / 41.8$ & $141 / 62.7$ & $145 / 84.3$ \\
\hline Maternity ward of Yakutsk & $86 / 40.4$ & $59 / 26.2$ & $4 / 2.3$ \\
\hline Central hospital of Ulus (CHU) & $31 / 14.6$ & $22 / 9.8$ & $23 / 13.3$ \\
\hline Other departments & $6 / 2.8$ & $3 / 1.3$ & - \\
\hline Self-appeal & $1 / 0.47$ & - & - \\
\hline Total & $213 / 100$ & $225 / 100$ & $172 / 100$ \\
\hline
\end{tabular}

The analysis of the health of newborns who had been admitted revealed that every year the number of babies in a very severe condition increased. In 2012, it was 39(18.3\%) newborns, in 2013 - 68(30.2\%) newborns, in 2014-67(38.9\%) newborns. In 2012, a severe condition was diagnosed for 130(61.03\%) newborns, in 2013 for 136 (60.4\%), in 2014 for 102(59.3\%) newborns (Table 3).

Table 3.

The health of newborns at admission to DPNaPB of PC-NCM

\begin{tabular}{|l|c|c|c|c|}
\hline \multicolumn{1}{|c|}{ Variable } & $\begin{array}{c}2012 \\
(\mathrm{n} / \%)\end{array}$ & $\begin{array}{c}2013 \\
(\mathrm{n} / \%)\end{array}$ & $\begin{array}{c}2014 \\
(\mathrm{n} / \%)\end{array}$ & $P$ \\
\hline Very severe condition & $39 / 18.3$ & $68 / 30.2$ & $67 / 38.9$ & 0.0000 \\
\hline Severe condition & $130 / 61.0$ & $136 / 60.4$ & $102 / 59.3$ & 0.9413 \\
\hline Moderate condition & $43 / 20.2$ & $19 / 8.4$ & $3 / 1.7$ & 0.0000 \\
\hline Satisfactory condition & $1 / 0.47$ & $2 / 0.89$ & - & 0.7870 \\
\hline Total & $213 / 100$ & $225 / 100$ & $172 / 100$ & \\
\hline
\end{tabular}

Dynamics starting from 2012 revealed an increase in the number of extremely serious conditions of newborns. This tendency is associated with an increase of the number of babies with gestation less than 28 weeks: in 2012 - 37 (17.3\%), in $2013-43(19.1 \%)$ and in $2014-38(22.1 \%)$ (Table 4). The huge growth of the number of hospitalized babies with ELBW 
and very low birth weight (VLBW) is revealed in annual dynamics. Thus, in 2012 the share of babies with ELBW was 31 ( $15 \%$ of all the cases of hospitalization), in $2013-30$ (13.3 $\%)$, in $2014-41$ (23.8\%) (Table 5).

\section{Table 4.}

Distribution of hospitalized babies by gestation term

\begin{tabular}{|l|c|c|c|c|c|c|}
\hline $\begin{array}{l}\text { Weeks of } \\
\text { gestation }\end{array}$ & $\begin{array}{c}2010 \\
(\mathrm{n} / \%)\end{array}$ & $\begin{array}{c}2011 \\
(\mathrm{n} / \%)\end{array}$ & $\begin{array}{c}2012 \\
(\mathrm{n} / \%)\end{array}$ & $\begin{array}{c}2013 \\
(\mathrm{n} / \%)\end{array}$ & $\begin{array}{c}2014 \\
(\mathrm{n} / \%)\end{array}$ & $P$ \\
\hline$<28$ & $20 / 8.2$ & $16 / 7.0$ & $37 / 17.4$ & $43 / 19.1$ & $38 / 22.1$ & 0.0000 \\
\hline $28-30$ & $41 / 16.4$ & $39 / 17.2$ & $55 / 25.8$ & $59 / 26.2$ & $69 / 40.1$ & 0.0000 \\
\hline $31-33$ & $107 / 43.7$ & $102 / 44.9$ & $85 / 39.9$ & $93 / 41.3$ & $55 / 32.0$ & 0.0887 \\
\hline $34-36$ & $67 / 27.3$ & $60 / 26.4$ & $31 / 14.6$ & $24 / 11$ & $10 / 5.8$ & 0.0000 \\
\hline$>36$ & $10 / 4.1$ & $10 / 4.4$ & $5 / 2.3$ & $6 / 2.6$ & - & 0.0734 \\
\hline Total & $245 / 100$ & $227 / 100$ & $213 / 100$ & $225 / 100$ & $172 / 100$ & \\
\hline
\end{tabular}

\section{Table 5.}

Distribution of hospitalized babies by weight at birth

\begin{tabular}{|l|c|c|c|c|c|c|}
\hline $\begin{array}{c}\text { Weight } \\
(\mathrm{g})\end{array}$ & $\begin{array}{c}2010 \\
(\mathrm{n} / \%)\end{array}$ & $\begin{array}{c}2011 \\
(\mathrm{n} / \%)\end{array}$ & $\begin{array}{c}2012 \\
(\mathrm{n} / \%)\end{array}$ & $\begin{array}{c}2013 \\
(\mathrm{n} / \%)\end{array}$ & $\begin{array}{c}2014 \\
(\mathrm{n} / \%)\end{array}$ & $P$ \\
\hline$>1000$ & $10 / 4.1$ & $22 / 9.7$ & $31 / 14.6$ & $30 / 13.3$ & $41 / 23.8$ & 0.0000 \\
\hline $1000-1250$ & $15 / 6.1$ & $27 / 11.9$ & $35 / 16.4$ & $34 / 15.1$ & $23 / 13.4$ & 0.0000 \\
\hline $1250-1500$ & $33 / 13.5$ & $36 / 15.8$ & $37 / 17.4$ & $45 / 20.0$ & $51 / 29.6$ & 0.0006 \\
\hline $1500-2000$ & $106 / 43.3$ & $90 / 39.6$ & $71 / 34.7$ & $84 / 37.3$ & $52 / 30.2$ & 0.0524 \\
\hline $2000-2500$ & $56 / 22.8$ & $46 / 20.3$ & $27 / 12.7$ & $18 / 8.0$ & $5 / 2.9$ & 0.0000 \\
\hline$>2500$ & $25 / 10.2$ & $6 / 2.6$ & $12 / 5.6$ & $14 / 6.2$ & - & 0.0000 \\
\hline Total & $245 / 100$ & $227 / 100$ & $213 / 100$ & $225 / 100$ & $172 / 100$ & \\
\hline
\end{tabular}

In 2012, the majority of newborns (55.39\%) in the Department of Pathology of Newborn and Premature Babies received artificial feeding, $28.63 \%$ received breastfeeding and 34 (15.96\%) received mixed feeding. In 2013, $108(50 \%)$ of newborns received artificial feeding, $64(30 \%)$ received breastfeeding and $44(20.3 \%)$ babies received mixed feeding. In 2014, $105(61 \%)$ babies received artificial feeding, 42 (24.4\%) received mixed feeding and only 25 (14.4\%) babies received breast milk. Such a tendency is due to severe and very severe conditions of the health of very preterm babies and hypo- and agalactia of mothers (Table 6).

Table 6.

Distribution of hospitalized babies according to feeding type

\begin{tabular}{|l|c|c|c|c|}
\hline \multicolumn{1}{|c|}{ Feeding type } & $\begin{array}{c}2012 \\
(\mathrm{n} / \%)\end{array}$ & $\begin{array}{c}2013 \\
(\mathrm{n} / \%)\end{array}$ & $\begin{array}{c}2014 \\
(\mathrm{n} / \%)\end{array}$ & $P$ \\
\hline Breastfeeding & $61 / 28.6$ & $64 / 28.4$ & $25 / 14.5$ & 0.0014 \\
\hline Mixed feeding & $34 / 16.0$ & $44 / 19.6$ & $42 / 24.4$ & 0.1160 \\
\hline Artificial feeding & $118 / 55.4$ & $117 / 52.0$ & $105 / 61.0$ & 0.1970 \\
\hline Total & $213 / 100$ & $225 / 00$ & $172 / 100$ & \\
\hline
\end{tabular}

In 2014, the most common disease in the structure of morbidity of hospitalized very preterm babies was perinatal lesion of central nervous system $(95.9 \%$ of cases, $5.8 \%$ of them were intraventricular hemorrhage of the third degree); respiratory distress syndrome was in $80.8 \%$ of the cases of morbidity, infectious and inflammatory diseases in $14.5 \%$ of the cases. The following complications were observed: necrotizing enterocolitis (11.0\%), conjugation hyperbilirubinemia $(16.8 \%)$, and anemia of prematurity (39.5\%).

According to the data obtained (Table 7), $57.1 \%$ of fatal outcomes belong to the babies with a term of gestation less than 28 weeks. On average, $75 \%$ of babies were born with ELBW.

Table 7.

The structure of hospital mortality among the premature infants

\begin{tabular}{|c|c|c|c|c|}
\hline Variable & Fatal outcomes & $\begin{array}{c}2013 \\
\mathrm{n}=8(\mathrm{n} / \%)\end{array}$ & $\begin{array}{c}2014 \\
\mathrm{n}=14(\mathrm{n} / \%)\end{array}$ & $P$ \\
\hline \multirow{3}{*}{ Age } & 0-6 days & - & - & \multirow{3}{*}{0.9643} \\
\hline & 6-28 days & $6 / 75$ & $9 / 64.28$ & \\
\hline & $>28$ days & $2 / 25$ & $5 / 35.71$ & \\
\hline \multirow{2}{*}{ Gender } & Boys & $6 / 75$ & $6 / 42.86$ & \multirow{2}{*}{0.3118} \\
\hline & Girls & $2 / 25$ & $8 / 57.14$ & \\
\hline \multirow{4}{*}{ Ethnicity } & Ethnic Russians & -- & $2 / 14.28$ & \multirow{4}{*}{0.9650} \\
\hline & Yakuts & $7 / 87.5$ & $11 / 78.57$ & \\
\hline & $\begin{array}{l}\text { Minority } \\
\text { ethnicities }\end{array}$ & $1 / 12.5$ & - & \\
\hline & Others & - & $1 / 7.14$ & \\
\hline \multirow[t]{2}{*}{ Residence } & Rural & $5 / 62.5$ & $7 / 50.0$ & \multirow{2}{*}{0.9025} \\
\hline & Urban & $3 / 37.5$ & $7 / 50.0$ & \\
\hline \multirow{3}{*}{$\begin{array}{l}\text { Route of } \\
\text { admission }\end{array}$} & $\begin{array}{l}\text { Maternity ward of } \\
\text { PC- NCM }\end{array}$ & $7 / 87.5$ & $13 / 92.85$ & \multirow{3}{*}{0.9175} \\
\hline & $\begin{array}{c}\text { City maternity } \\
\text { ward }\end{array}$ & $1 / 12.5$ & - & \\
\hline & $\mathrm{CHU}$ & - & $1 / 7.14$ & \\
\hline \multirow{4}{*}{$\begin{array}{l}\text { Term of } \\
\text { gestation }\end{array}$} & $<28$ weeks & $5 / 62.5$ & $8 / 57.14$ & \multirow{4}{*}{0.8376} \\
\hline & 28-30 weeks & $3 / 37.5$ & $6 / 42.85$ & \\
\hline & 31-33 weeks & - & - & \\
\hline & 34-37 weeks & - & - & \\
\hline \multirow{4}{*}{$\begin{array}{l}\text { Weight at } \\
\text { birth (g) }\end{array}$} & $<1000$ & $4 / 50.0$ & $12 / 85.71$ & \multirow{4}{*}{0.1678} \\
\hline & $1000-1250$ & $1 / 12.5$ & $2 / 14.28$ & \\
\hline & $1250-1500$ & $3 / 37.5$ & - & \\
\hline & $1500-2500$ & - & - & \\
\hline
\end{tabular}

According to autopsies, the causes of mortality were the following: respiratory distress syndrome $(37.5 \%)$, congenital pneumonia (12.5\%), intraventricular hemorrhage of the third degree/noncommunicating hydrocephaly/coma (12.5\%), respiratory syncytial virus infection (12.5\%), a congenital heart defect (complete transposition of the great vessels) (12.5\%), and neonatal necrotizing enterocolitis $(12.5 \%)$.

\section{Conclusion}

The group at risk of VEPB consisted of women with burdened obstetric and gynecological history. The main causes of VEPB were premature amniorrhexis in pregnant women with carriage of infections and life-threatening severe pre- 
eclampsia. In the structure of morbidity of very preterm babies the first place among the main diseases belongs to perinatal lesion of central nervous system, the second place belongs to respiratory distress syndrome, and the third place to infectious and inflammatory diseases. In the structure of death, $57.1 \%$ of fatal cases are babies with a term of gestation less than 28 weeks.

Thus, implementation of routing of pregnant women with severe extragenital pathology who have a risk of PB has an opportunity to significantly reduce the medical and social effects of VEPB.

\section{Competing interests}

The authors declare that they have no competing interests.

\section{References}

1. Sidelnikova VM. Proceedings of the 8th Russian Forum "Mother and Child". M.: 2006: 241 [in Russian].

2. Sidelnikova VM, Antonov AG. Preterm birth. Premature baby. Guide for physicians. M.: GEOTAR-Media; 2008.

3. Kulakov VI, Antonov AG, Baibanna EN. Problems and perspectives of care for very low body-weight babies at the present stage. Ross Vest Perinat Ped. 2006;4:8-11.[in Russian]. 4. Kryvkina NN, Akhmadeyeva EN, Valyulina AYa. The comparative characteristics of health premature infants depending on theirs birth weight. Vest Sovremen Klin Med. 2013; 6(1):26-30.[in Russian].

5. Order of the Health Ministry of Russia №1687n of December 27, 2011. "On the medical criteria of birth, the form of the birth order and its issuance". [in Russian]. 